\title{
THE MORPHOLOGICAL STABILITY OF INTERNAL MELTING FIGURES IN ICE
}

\author{
By Shinji MAE \\ (National Institute of Polar Research, I-9-Io Kaga, Itabashi-ku, Tokyo, Japan)
}

Abstract. Wavy perturbations formed on disc-shaped internal melting figures in ice were observed. It was found that a minimum wavelength of the perturbations was approximately I $00 \mu \mathrm{m}$ and a critical thickness of the figures for the formation of the perturbations was Io $\mu \mathrm{m}$. The critical thickness did not depend on the radius and growth rate of the figures. A minimum wave number of the perturbation was 6 and the axis of its sixfold symmetry was parallel to the $\left\langle\mathrm{I} \mathrm{I}_{\mathbf{2}} \mathrm{O}\right\rangle$ direction. The perturbations with large wave number were formed on the inclined side faces of internal melting figures of which the shape was like a truncated cone. Therefore, it was concluded that the perturbations were nucleated at the sharp edge where the side face and the larger plane of the figures intersected. This conclusion was supported by the observation of internal melting figures at grain boundaries where their periphery was always sharp. 